\title{
Correction to: Dietary Proteins Alter Fermentation Characteristics of Human Gut Microbiota In Vitro
}

\author{
Tianzhen Xiao ${ }^{1} \cdot$ Tingting Liang $^{2} \cdot$ Dong-Hui Geng ${ }^{1} \cdot$ Lili Wang $^{1} \cdot$ Liya Liu $^{1} \cdot$ Xianrong Zhou $^{1} \cdot$ Huayin Pu $^{2}$. \\ Junrong Huang ${ }^{2}$. Sumei Zhou ${ }^{1} \cdot$ Li-Tao Tong $^{1}$ (D)
}

Published online: 26 November 2021

๑) Springer Science+Business Media, LLC, part of Springer Nature 2021

\section{Correction to: Plant Foods for Human Nutrition (2020) https://doi.org/10.1007/s11130-020-00836-w}

The original version of this article unfortunately contained a mistake. Article Title, Abstract and Keywords has been published in non english version. Thus, erratum is presented to fix this error.

The original article has been corrected.

Publisher's Note Springer Nature remains neutral with regard to jurisdictional claims in published maps and institutional affiliations.

The original article can be found online at https://doi.org/10.1007/ s11130-020-00836-w.

Li-Tao Tong tonglitao@caas.cn

1 Chinese Academy of Agricultural Sciences, Key Laboratory of Agro-Products Processing, Ministry of Agriculture, Institute of Agro-Products Processing Science and Technology, Beijing 100193, China

2 School of Food and Biological Engineering, Shaanxi University of Science and Technology, Xi' an 710021, China 